Tensor Analysis for Physicists

By Prof. J. A. Schouten. Pp. $x+276$. (Oxford: Clarendon Press ; London : Oxford University Press, 1951.) 30s. net.

THIS great work by Prof. J. A. Schouten will be welcomed as a modern exposition of a subject which he has already treated in his classical monograph, "Der Ricci-Kalkül", published in 1924 by Springer. It also incorporates the work which he published in collaboration with Struik in 1935 and 1938, entitled "Einführung in die neueren Methoden der Differential-Gcometrie : I, II".

The subject is expounded in a monumental manner, and the physicist will find that he is compelled to observe the full rigour of the game. The treatment is full and exhaustive: Schouten's theory of a "geometric object" is given in full, and the tensor analysis is throughout made subservient to the theory of linear groups. The second half of the book is devoted to physical applications of the theory, and it includes the theory of elasticity, classical dynamics, relativity, and Dirac's matrix calculus. There is probably no other book which covers the same ground in such extent and in such detail. It will be indispensable to the mathematical physicist for many years to come, but he will probably use it as a work of reference rather than as an introduction to the subject. Even the convenient summary of the first five chapters, which is given by the author because it "was specially asked for by physicists", presents a very forbidding aspect to those who have learnt their tensor calculus in order to study the special and general theories of relativity.

However, there is no doubt that the work richly repays detailed study, and both physicists and mathematicians are greatly indebted to the author for giving them the fruits of a lifetime's meditation on this important mathematical technique.

Mechanical Vibrations

By Prof. William Tyrrell Thomson. Pp. viii +222. (London: George Allen and Unwin, Itt., 1950.) 15s. net.

The Theory of Vibrations

For Engineers. By E. B. Cole. Second revised edition. Pp. 334. (London: Crosby Lockwood and Son, Ltd., 1950.) 18s. net.

DROF. W. T. Thomson's book contains a clear account of vibration theory. The first four chapters cover the free and forced vibration of systems having one degree of freedom. These chapters will provide the third-year honours engineering student with all the material that he requires on this subject, an elementary knowledge of the calculus and differential equations, including the use of the $j$ operator, being assumed. 'The later chapters cover more advanced work, including the differential equations for elastic-body vibration, and various methods for the calculation of the frequencies of complicated systems, such as iteration and Myklestadt's process. 'These chapters will be most valuable for the student who wishes to specialize. The treatment throughout the book is sound and lucid, and the diagrams are good. A large number of examples are included.

Mr. E. B. Cole's book is designed for those with less mathematical knowledge. It has been very considerably enlarged since the first edition appeared in 1935. It begins with an explanation of simple harmonic motions and the use of rotating vectors.
The later chapters cover the calculation of torsional vibration frequencies in engines, the whirling speeds of shafts and the flexural vibration of beams. It will be of use to those who need frequency calculations in design work. Many of the examples quoted are of practical interest; a number of references to papers are included at appropriate places in the text.

D. C. JOHNSON

\section{Man and Matter}

Fissays Scientific and Christian. By Dr. F. Sherwood Taylor. Pp. 238. (London: Chapman and Hall, Ltd., 1951.) 15s. net.

MOST of these essays are biographical in the V sense that the author is defining and defending his position as a student of science and a Roman Catholic. The first is explicitly so ; describing how he reacted against the formalistic religion of his home and school, took up science as a career along with the positivist creed which seemed to go with it, discovered that half his nature was unsatisfied, and after going far afield to oriental mysticism for what he wanted found it nearer home. Out of this devious inquiry comes one of the most interesting of his essays, "Mystieism, Christian and Pagan". The titles, "The Deficiencies of Materialism"; "Science, Philosophy and Religion"; "Biology and Man"; "Evolution and Religion"; "The Vocation of Science" ; "The Church and Science", indicate the scope of Dr. Sherwood Taylor's exposition. The essay on "The Problem of Pain in Nature" is too slight to do justice to one of the knottiest of all problems. On the other hand, the one "On the Excellence of Things" explains, with apt quotations from Western poets and Chinese sages, just what scientific men tend to forget. The essay on "Some Moral Problems Raised by Science" makes the point that positivists frequently claim that natural science could provide answers to moral questions out of its own resources, but fail to show how it can be done in any specific case. "The Place of Science in Christian Education" is to be commended, specially for its criticism of the artificiality and abstractness of a great deal of actual teaching.

A. D. R.

\section{The Faith of a Fieldsman}

By H. J. Massingham. Pp. $271+17$ plates. (London : Museum Press, Ltd., 1951.) 15s, net.

I. J. MASSINGHAM has long been known as a writer on life in the countryside. In his latest book, "The Faith of a Fieldsman", he returns to this well loved theme, his pen roving over a wide variety of topics concerning the land, particularly English land, and those whose lot it is to tend it and live on it. In short, chatty chapters, he discusses this and that, dividing his subject matter into sections, "Country Life and Culture", "The Farming Scene", and so on, the last section being devoted to "A Few Verses". Mr. Massingham sees much virtue in many things, things that are passing with the changing times, such as the old village craftsmen and goodly hedges between the fields, and correspondingly little virtue in the doings of this mechanized generation. Those of us who likewise love the old English countryside will enjoy his gibes and shrewd thrusts, even if at the same time we recognize that change is the essence of life, and even the slow-to-move communities of village and farm are not immune from the trend of the times, which indeed must be the case if they are to survive in any form, whether in their old or s ime new shape. Frances PitT 